\title{
Knowledge-based sea ice classification by polarimetric SAR
}

\author{
Skriver, Henning; Dierking, Wolfgang
}

Published in:

IEEE International Geoscience and Remote Sensing Symposium, 2004. IGARSS '04. Proceedings.

Link to article, DOI:

10.1109/IGARSS.2004.1368995

Publication date:

2004

Document Version

Publisher's PDF, also known as Version of record

Link back to DTU Orbit

Citation $(A P A)$ :

Skriver, H., \& Dierking, W. (2004). Knowledge-based sea ice classification by polarimetric SAR. In IEEE International Geoscience and Remote Sensing Symposium, 2004. IGARSS '04. Proceedings. IEEE. https://doi.org/10.1109/IGARSS.2004.1368995

\section{General rights}

Copyright and moral rights for the publications made accessible in the public portal are retained by the authors and/or other copyright owners and it is a condition of accessing publications that users recognise and abide by the legal requirements associated with these rights.

- Users may download and print one copy of any publication from the public portal for the purpose of private study or research.

- You may not further distribute the material or use it for any profit-making activity or commercial gain

- You may freely distribute the URL identifying the publication in the public portal

If you believe that this document breaches copyright please contact us providing details, and we will remove access to the work immediately and investigate your claim 


\section{Knowledge-Based Sea Ice Classification by Polarimetric SAR}

\author{
Henning Skriver \\ Ørsted•DTU Department \\ Technical University of Denmark \\ Kgs. Lyngby, Denmark \\ hs@oersted.dtu.dk
}

\author{
Wolfgang Dierking \\ Alfred Wegener Institute for Polar and Marine Research \\ Bremerhaven, Germany
}

\begin{abstract}
Polarimetric SAR images acquired at C- and L-band over sea ice in the Greenland Sea, Baltic Sea, and Beaufort Sea have been analysed with respect to their potential for ice type classification. The polarimetric data were gathered by the Danish EMISAR and the US AIRSAR which both are airborne systems. A hierarchical classification scheme was chosen for sea ice because our knowledge about magnitudes, variations, and dependences of sea ice signatures can be directly considered. The optimal sequence of classification rules and the rules themselves depend on the ice conditions/regimes. The use of the polarimetric phase information improves the classification only in the case of thin ice types but is not necessary for thicker ice (above about 30 cm thickness).
\end{abstract}

Keywords-component; polarimetric SAR, sea ice, ice types, classification, knowledge-based

\section{INTRODUCTION}

In the near future a number of polarimetric SAR satellites will be launched, e.g. the Japanese ALOS, and the Canadian Radarsat-2. Multi-frequency and polarimetric SAR images acquired from airborne and spaceborne sensors during the last 15 years have shown a promising potential for the classification of sea ice types (e.g. [1]). Hereby, the combination of different frequencies seems to have a more pronounced effect on the improvement of the ice type discrimination than the utilization of the available intensity and phase data at one frequency band. Since the operation and application of a fully polarimetric system is more costly than the measurement and use of multi-polarization intensity data, a critical examination is necessary of the advantage gained by including the phase information. Investigations both at $\mathrm{C}$ - and L-band suggest that the polarimetric phase is related to the thickness of thin ice $0-0.3 \mathrm{~m}$ thick [2][3][4][5]. Thin ice areas play an important role for the heat and salt fluxes in icecovered oceans. Hence, a potential and promising application of polarimetric SAR could be the monitoring of new ice growth.

Polarimetric SAR images acquired at C- and L-band over sea ice in the Greenland Sea, Baltic Sea, and Beaufort Sea have been analysed with respect to their potential for ice type classification. The polarimetric data were gathered by the Danish EMISAR and the US AIRSAR which both are airborne systems. For the test sites, complementary data about the characteristics of the ice cover and about the environmental conditions are available.

Because of the highly dynamic backscattering characteristics of an ice cover, which depend on environmental conditions (for example, weather, geographical region, ocean parameters), we favour a knowledge-based classification approach that can be optimally adapted to the particular region and season. In addition, the approach can be more easily devised according to the actual user needs, for example, by focussing on specific ice types and ice features.

In Section II the three test sites are described. The methodology used is outlined in Section III, and Section IV contains the classification results. Finally, Section V presents the conclusions.

\section{DATA}

\section{A. Greenland Sea}

The images used were acquired on March 24, 1995, at Cband by the Danish EMISAR along a north-south strip at the East coast of Greenland. Altogether, 5 scenes were processed each of which covers an area of about $12 \times 20 \mathrm{~km}^{2}$. The SAR incidence angles varied from $37 \mathrm{deg}$ to $61 \mathrm{deg}$. The air temperatures were around $-20^{\circ} \mathrm{C}$, and the wind speed was less than $12 \mathrm{~m} / \mathrm{s}$ [6]. In the EMISAR images a variety of ice types is seen, consisting of different thin ice classes in freezing leads, and distinct multi-year ice floes with ridges (cf. Fig. 1). Many ridges are much shorter compared to the Beaufort Sea ice scenes described below, and with a random orientation. The reason is that the Greenland Sea ice floes consist of smaller fragments and have a weathered surface.

\section{B. Baltic Sea}

The EMISAR scenes used for the Baltic Sea were acquired during EMAC (European Multisensor Airborne Campaign) on March 22 (L-band) and March 23 (C-band), 1995. Over the swath, the radar incidence angle changed from 40 to $60 \mathrm{deg}$. The air temperatures varied between $-5^{\circ} \mathrm{C}$ and $-10^{\circ} \mathrm{C}$. On the day before the flight campaigns, however, it had been above freezing point. In-situ ice data acquired on one spot at test site 3 on March 22 revealed an ice thickness of $0.26 \mathrm{~m}$ and an ice salinity of $0.23 \mathrm{ppt}$ (formed in brackish water it is much lower

The study is funded partly under ESA contract 


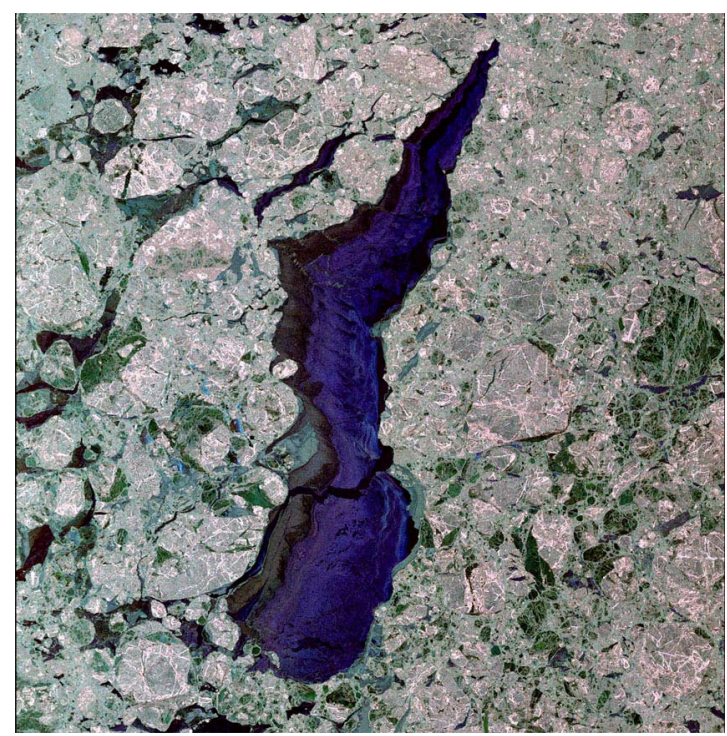

Figure 1. EMISAR image from the Greenland Sea (C-band)

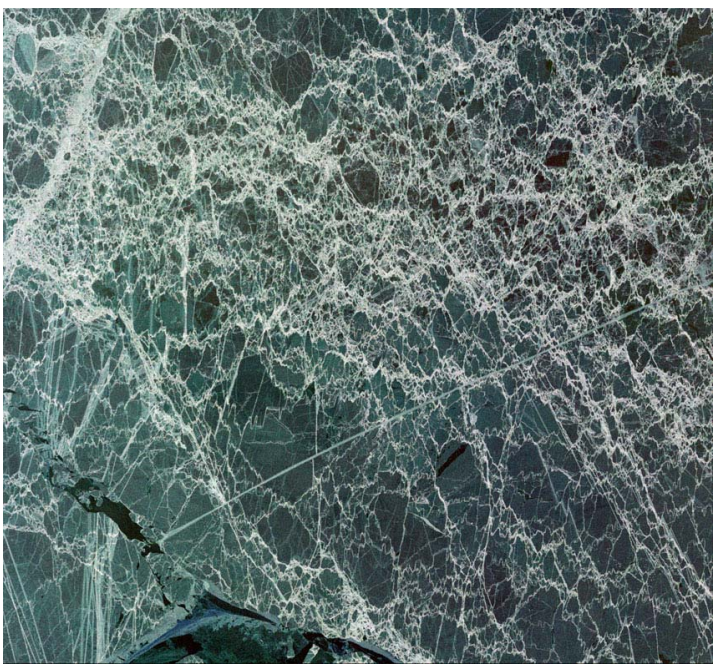

Figure 2. EMISAR image from the Baltic Sea (L-band)

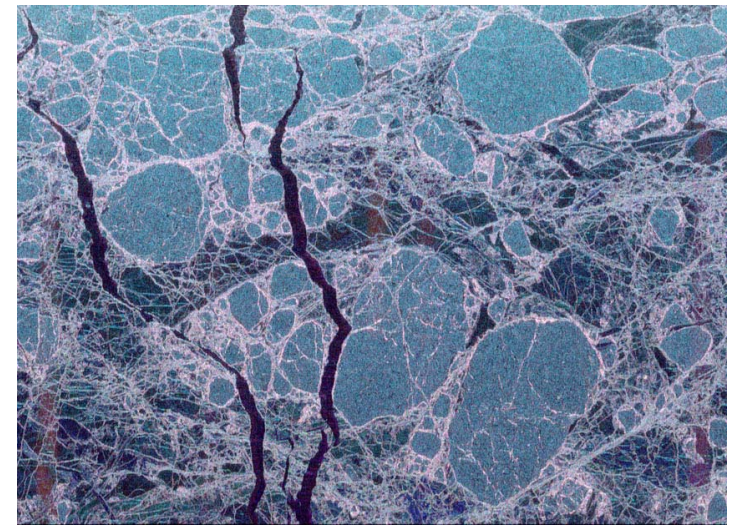

Figure 3. AIRSAR image from the Beaufort Sea (L-band, CM1372)

than the salinity of FY ice typically observed in the Arctic). The ice was snow covered (layer thickness $5 \mathrm{~cm}$, density 0.2 $\mathrm{g} / \mathrm{cm}^{3}$ ) [7]. The ice cover consists of ridged ice with almost no open water and/or narrow leads (cf. Fig. 2). The level ice between the ridges appears rather homogeneous.

\section{Beaufort Sea}

The images used for our study (i.e. CM137, CM1372, CM183, and CM291) were acquired on March 11, 1988 simultaneously at three different frequency bands (C-, L-, and P-band) by the US AIRSAR. For the present analysis, we did not consider P-band. Meteorological data were collected within a $150 \mathrm{~km}$ radius of an ice camp. The air temperature varied between $-12^{\circ} \mathrm{C}$ and $-18^{\circ} \mathrm{C}$ on the day of the SAR flight, after predominantly lower values during the preceding week [1], [2], [8]. The SAR images show a mixture of different ice types (cf. Fig. 3). Rounded, large multi-year ice floes are dominant in all scenes. Significant deformation is revealed in first-year ice surrounding the multi-year ice floes with the presence of a dense and complex network of rubble fields and ridges over the whole area. New cracks and leads are present, created by divergent motion of the ice. The newly frozen ice in leads is relatively undeformed, indicating that little convergence occurred after freeze-up.

\section{METHOD}

We have selected to base the classification procedure on a knowledge-based hierarchical approach. The advantage of such an approach compared to a statistical classification method is that it is easy to include available information/knowledge of sea ice radar signatures, their variability, and their dependencies on environmental conditions in the classification process. By combining the hierarchical scheme with a statistical method in order to determine the decision boundaries at the individual levels in the hierarchy, it is possible to adapt the classification scheme to the actual data at hand. A major disadvantage of such an approach is that it relies on a correct identification of the information-bearing features.

In a first step, we evaluated different polarimetric parameters for different ice classes (i.e. multi-year ice: MY, first-year ice: FY, and thin ice: TH). The ice classification was carried out subjectively using the radar intensity images and complementary information. Both MY and FY ice were separated in level and ridged ice. Within classes MY and TH, different radar signatures could be distinguished. We took these as sub-classes, but because of the lack of corresponding in-situ data, it was not possible to link sub-classes to certain physical ice properties. All polarimetric parameters were plotted as a function of ice type. On the basis of the plots, we devised knowledge-based classification strategies. Since the discrimination performance of different polarimetric parameters varies between the three test sites, and since the ice conditions (in terms of ice type mixture and ice characteristics) are different, we developed separate classification schemes. The decision rules determined from this analysis are listed for the three test sites in Tables I-III [9]. Also, in order to test the necessity and the possibility of adjusting the decision rules in the classification scheme, a MAP ISODATA classifier was used with the result of the direct hierarchical classification scheme as input. 
TABLE I. DECISION RULES FOR GREENLAND SEA

\begin{tabular}{|l|l|}
\hline \multicolumn{1}{|c|}{ Ice Type } & \multicolumn{1}{c|}{ Classification Rules } \\
\hline Ridges & $\sigma_{\mathrm{VV}}^{0} / \sigma_{\mathrm{HH}}^{0}<2 \mathrm{~dB}$ and $\sigma_{\mathrm{HV}}^{0}>-18 \mathrm{~dB}$ \\
\hline MY-Ice 1 & $\sigma_{\mathrm{VV}}^{0} / \sigma_{\mathrm{HH}}^{0}<1.2 \mathrm{~dB}$ and $\sigma_{\mathrm{HV}}^{0}>-27.5 \mathrm{~dB}$ \\
\hline MY-Ice 2 & $\sigma_{\mathrm{VV}}^{0} / \sigma_{\mathrm{HH}}^{0}<1.2 \mathrm{~dB}$ and $\sigma_{\mathrm{HV}}^{0} \leq-27.5 \mathrm{~dB}$ \\
\hline Thin Ice 1-3 & $\sigma_{\mathrm{VV}}^{0} / \sigma_{\mathrm{HH}}^{0} \geq 1.2 \mathrm{~dB}$ and $\phi_{\mathrm{HHV}} \geq 15^{\circ}$ \\
\hline Thin Ice 4 & $\begin{array}{l}\sigma_{\mathrm{VV}}^{0} / \sigma_{\mathrm{HH}}^{0} \geq 1.2 \mathrm{~dB} \text { and } \phi_{\mathrm{HHVV}} \leq 15^{\circ} \\
\text { and } \sigma_{\mathrm{HV}}^{0} /\left(\sigma_{\mathrm{VV}}^{0}+\sigma_{\mathrm{HH}}^{0}\right)>-15 \mathrm{~dB}\end{array}$ \\
\hline Open Water & $\begin{array}{l}\sigma_{\mathrm{VV}}^{0} / \sigma_{\mathrm{HH}}^{0} \geq 1.2 \mathrm{~dB} \text { and } \phi_{\mathrm{HHVV}} \leq 15^{\circ} \\
\text { and } \sigma_{\mathrm{HV}}^{0} /\left(\sigma_{\mathrm{VV}}^{0}+\sigma_{\mathrm{HH}}^{0}\right) \leq-15 \mathrm{~dB}\end{array}$ \\
\hline
\end{tabular}

TABLE II. DECISION RULES For BALTIC SEA

\begin{tabular}{|c|c|c|}
\hline $\begin{array}{l}\text { Ice Type } \\
\end{array}$ & L-Band & C-Band \\
\hline $\begin{array}{l}\text { Ridged } \\
\text { Fragmented Ice }\end{array}$ & $\begin{array}{l}\sigma_{\mathrm{VV}}^{0}>-15 \mathrm{~dB}^{(1)} \text { and } \\
\sigma_{\mathrm{HV}}^{0}>-20 \mathrm{~dB} \text { and } \\
\phi_{\mathrm{HHVV}} \leq 15^{\circ(3)}\end{array}$ & $\begin{array}{l}\sigma_{\mathrm{HH}}^{0}>-16 \mathrm{~dB} \text { and } \\
\sigma_{\mathrm{VV}}^{0} / \sigma_{\mathrm{HH}}^{0} \leq 1 \mathrm{~dB}\end{array}$ \\
\hline $\begin{array}{l}\text { Deformed Ice } \\
\text { ("Bright Ice") }\end{array}$ & $\begin{array}{l}\sigma_{\mathrm{VV}}^{0}>-17 \mathrm{~dB}^{(1)} \text { and } \\
\sigma_{\mathrm{HV}}^{0} \leq-20 \mathrm{~dB} \text { and } \\
\phi_{\mathrm{HHVV}} \leq 15^{\circ}(3)\end{array}$ & $\begin{array}{l}\sigma_{\mathrm{HH}}^{0}>-16 \mathrm{~dB} \text { and } \\
\sigma_{\mathrm{VV}}^{0} / \sigma_{\mathrm{HH}}^{0} \leq 1 \mathrm{~dB}{ }^{(4)}\end{array}$ \\
\hline Level Ice & $\begin{array}{l}-27 \mathrm{~dB}<\sigma_{\mathrm{VV}}^{0} \leq-17 \mathrm{~dB} \\
\text { and } \\
-36 \mathrm{~dB}<\sigma_{\mathrm{HV}}^{0} \leq-27 \mathrm{~dB} \\
\text { and } \phi_{\mathrm{HHVV}}>15^{\circ}(3)\end{array}$ & $\begin{array}{l}-25 \mathrm{~dB}<\sigma_{\mathrm{HH}}^{0} \leq-16 \mathrm{~dB} \\
\text { and } \\
\sigma_{\mathrm{VV}}^{0} / \sigma_{\mathrm{HH}}^{0}>1 \mathrm{~dB}\end{array}$ \\
\hline Thin Ice $^{(2)}$ & $\begin{array}{l}\sigma_{\mathrm{VV}}^{0} \leq-27 \mathrm{~dB}^{(1)} \\
\phi_{\mathrm{HHVV}}>15^{\circ}(3)\end{array}$ & $\begin{array}{l}\sigma_{\mathrm{HH}}^{0} \leq-25 \mathrm{~dB} \text { and } \\
\sigma_{\mathrm{VV}}^{0} / \sigma_{\mathrm{HH}}^{0}>4 \mathrm{~dB}^{(3)}\end{array}$ \\
\hline
\end{tabular}

(1) will also work with $\sigma_{\mathrm{HH}}^{0}$; ${ }^{(2)}$ not representative because of the small number of samples; ${ }^{(3)}$ only supplementary, not necessary; ${ }^{(4)}$ difficult to distinguish from ridged and fragmented ice for all analysed polarimetric parameters

TABLE III. DECISION RULES FOR BEAUFORT SEA

\begin{tabular}{|l|l|l|}
\hline \multicolumn{1}{|c|}{ Ice Type } & \multicolumn{1}{|c|}{ L-Band } & \multicolumn{1}{|c|}{ C-Band } \\
\hline MY Ice, Ridges & $\sigma_{\mathrm{VV}}^{0}>-11 \mathrm{~dB}$ and & $\sigma_{\mathrm{VV}}^{0}>-11 \mathrm{~dB}$ and \\
& $\sigma_{\mathrm{HV}}^{0}>-21 \mathrm{~dB}$ & $\sigma_{\mathrm{HV}}^{0}>0.73 \sigma_{\mathrm{vV}}^{0}-14.4[\mathrm{~dB}]$ \\
\hline FY Ice, Ridges & $\sigma_{\mathrm{VV}}^{0}>-15 \mathrm{~dB}$ and & $\sigma_{\mathrm{VV}}^{0}>-22 \mathrm{~dB}$ and \\
& $-28 \mathrm{~dB}<\sigma_{\mathrm{HV}}^{0} \leq-21 \mathrm{~dB}$ & $\sigma_{\mathrm{HV}}^{0} \leq 0.73 \sigma_{\mathrm{VV}}^{0}-17[\mathrm{~dB}]$ and \\
& $\sigma_{\mathrm{HV}}^{0}>-35 \mathrm{~dB}$ \\
\hline MY Ice, Level & $\sigma_{\mathrm{VV}}^{0}>-18 \mathrm{~dB}$ and & $\sigma_{\mathrm{VV}}^{0}>-11 \mathrm{~dB}$ and \\
& $\sigma_{\mathrm{HV}}^{0} \leq-28 \mathrm{~dB}$ & $\sigma_{\mathrm{HV}}^{0} \leq 0.73 \sigma_{\mathrm{VV}}^{0}-14.4[\mathrm{~dB}]$ and \\
\hline FY Ice, Level & $-27 \mathrm{~dB}<\sigma_{\mathrm{VV}}^{0} \leq-18 \mathrm{~dB}$ & $-28 \mathrm{~dB}<\sigma_{\mathrm{VV}}^{0} \leq-16 \mathrm{~dB}$ and \\
& and $\sigma_{\mathrm{HV}}^{0} \leq-28 \mathrm{~dB}$ & $\sigma_{\mathrm{HV}}^{0} \leq-35 \mathrm{~dB}$ \\
\hline Thin Ice, Type & $\sigma_{\mathrm{VV}}^{0} \leq-27 \mathrm{~dB}$ and & $\sigma_{\mathrm{VV}}^{0} \leq-28 \mathrm{~dB}$ and \\
& $\sigma_{\mathrm{HV}}^{0} \leq-28 \mathrm{~dB}$ & $\sigma_{\mathrm{HV}}^{0} \leq-35 \mathrm{~dB}$ \\
\hline Thin Ice, Type & $-18 \mathrm{~dB}<\sigma_{\mathrm{VV}}^{0} \leq-12 \mathrm{~dB}$ & $\begin{array}{l}\text { cannot be discriminated from } \\
\text { analysed polarimetric } \\
\text { parameters }\end{array}$ \\
\hline
\end{tabular}

\section{CLASSIFICATION RESULTS}

A pixel-based hierarchical classification approach has been applied to the SAR data. First, the rules from Section III are applied to the individual pixels to obtain an initial classification of the data. Hereafter, an ISODATA classifier is applied to all pixels to obtain the final classification result. The rule-based initial classification result is used to initialise the ISODATA classifier. The initial classification result is rather close to the final result and hence, the ISODATA classifier only needs to

TABLE IV. CONF. MAT. FOR GREENLAND SEA (OVERALL: 88\%)

\begin{tabular}{||c|r|r|r|r|r|r||}
\hline \hline CLASS & \multicolumn{1}{|c|}{ Ridge } & MY 1 & \multicolumn{1}{c|}{ MY 2 } & TH 1-3 & TH 4 & Water \\
\hline Ridge & 88.7 & 10.6 & 0.0 & 0.0 & 0.0 & 0.0 \\
\hline MY 1 & 1.9 & 75.3 & 3.3 & 0.8 & 0.0 & 0.0 \\
\hline MY 2 & 0.1 & 12.9 & 94.9 & 6.7 & 6.4 & 0.0 \\
\hline Thin 1-3 & 3.3 & 0.3 & 0.1 & 86.8 & 2.6 & 0.0 \\
\hline Thin 4 & 6.0 & 0.6 & 0.5 & 1.8 & 78.5 & 0.0 \\
\hline Water & 0.1 & 0.3 & 1.1 & 3.9 & 12.5 & 100.0 \\
\hline TOTAL & 100.0 & 100.0 & 100.0 & 100.0 & 100.0 & 100.0 \\
\hline
\end{tabular}

TABLE V. CONF. MAT. FOR BALTIC SEA (L-BAND) (OVERALL: 95\%)

\begin{tabular}{||c|r|r|r||}
\hline CLASS & \multicolumn{1}{|c|}{ Ridge } & \multicolumn{1}{c|}{ Level ice } & \multicolumn{1}{c|}{ Thin ice } \\
\hline Ridge & 90.7 & 0.1 & 0.0 \\
\hline Level ice & 9.3 & 96.9 & 0.2 \\
\hline Thin ice & 0.0 & 3.0 & 99.8 \\
\hline TOTAL & 100.0 & 100.0 & 100.0 \\
\hline
\end{tabular}

TABLE VI. CONF. MAT. For BALtiC SEA (C-BAND) (OVERALl: 87\%)

\begin{tabular}{||c|r|r|r||}
\hline CLASS & \multicolumn{1}{|c|}{ Ridge } & \multicolumn{1}{c|}{ Level ice } & \multicolumn{1}{c|}{ Thin ice } \\
\hline Ridge & 91.6 & 14.9 & 0.6 \\
\hline Level ice & 8.4 & 85.1 & 2.2 \\
\hline Thin ice & 0.0 & 0.0 & 97.2 \\
\hline TOTAL & 100.0 & 100.0 & 100.0 \\
\hline
\end{tabular}

TABLE VII. CONF. MAT. FOR BEAUFORT SEA (L-BAND) (OVERALL: 86\%)

\begin{tabular}{||c|r|r|r|r|r||}
\hline CLASS & \multicolumn{1}{c|}{$\begin{array}{c}\text { MY } \\
\text { Ridge }\end{array}$} & $\begin{array}{c}\text { FY } \\
\text { Ridge }\end{array}$ & \multicolumn{1}{c|}{ MY } & \multicolumn{1}{c|}{ FY } & Thin ice \\
\hline MY Ridge & 65.5 & 10.5 & 0.2 & 0.0 & 0.2 \\
\hline FY Ridge & 30.3 & 61.9 & 2.6 & 1.2 & 1.3 \\
\hline MY & 4.1 & 26.1 & 97.1 & 27.0 & 3.8 \\
\hline FY & 0.1 & 1.6 & 0.0 & 71.0 & 50.7 \\
\hline Thin ice & 0.0 & 0.0 & 0.0 & 0.7 & 44.0 \\
\hline TOTAL & 100.0 & 100.0 & 100.0 & 100.0 & 100.0 \\
\hline
\end{tabular}

TABLE VIII. CONF. MAT. FOR BEAUFort SEA (C-BAND) (OVERALl: 84\%)

\begin{tabular}{||c|r|r|r|r|r||}
\hline \hline CLASS & $\begin{array}{c}\text { MY } \\
\text { Ridge }\end{array}$ & $\begin{array}{c}\text { FY } \\
\text { Ridge }\end{array}$ & MY & FY & Thin ice \\
\hline MY Ridge & 50.0 & 3.4 & 8.9 & 0.1 & 0.3 \\
\hline FY Ridge & 2.9 & 51.0 & 0.2 & 7.6 & 7.2 \\
\hline MY & 47.0 & 39.1 & 90.9 & 1.2 & 2.1 \\
\hline FY & 0.2 & 6.6 & 0.0 & 88.9 & 54.3 \\
\hline Thin ice & 0.0 & 0.0 & 0.0 & 2.1 & 36.1 \\
\hline TOTAL & 100.0 & 100.0 & 100.0 & 100.0 & 100.0 \\
\hline
\end{tabular}

adjust the class centres slightly. Therefore, potential problems with the ISODATA scheme of labelling and clustering around unwanted centres are to a high degree avoided. The classification scheme is applied to covariance matrix data, which have been speckle reduced using a powerful simulated 
annealing method, resulting in equivalent number of looks of more than 50 [10]. Hence, classification errors are only to a very small degree caused by speckle noise.

The confusion matrices resulting from the initial classification for the three data sets are shown in Tables IVVIII, where the columns indicate the "true" classes and the rows indicate the assigned classes. Also, classified images

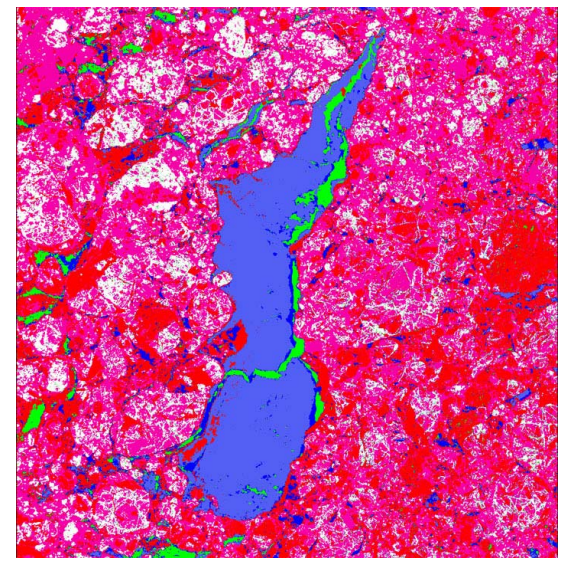

Figure 4. EMISAR Greenland Sea (white: ridges, purple: MY 1, red: MY 2, light blue: TH 1-3, green: TH 4, dark blue: open water)

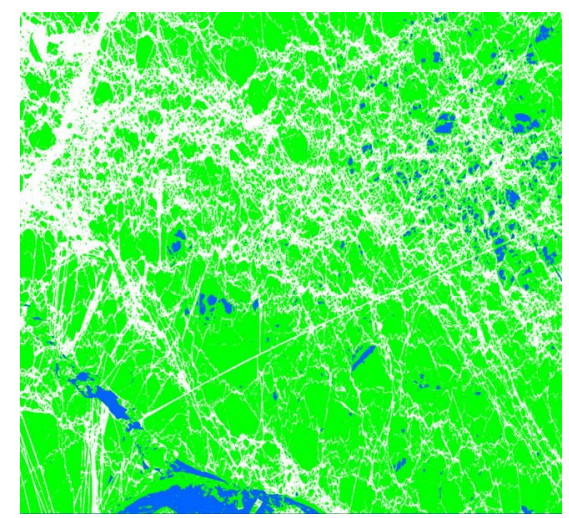

Figure 5. EMISAR L-band Baltic Sea (white: ridges, green: level, blue: thin)

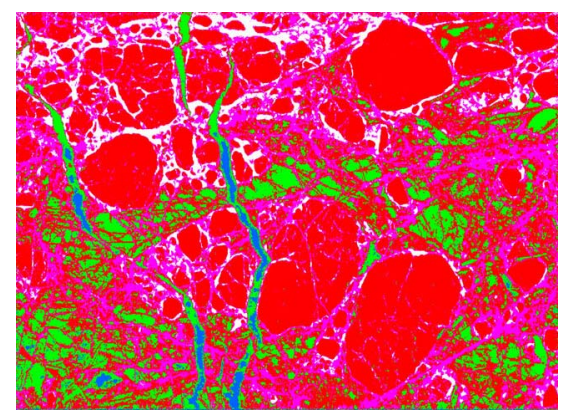

Figure 6. AIRSAR L-band Beaufort Sea (white: multiyear ridges, purple: first-year ridges, red: multiyear ice, green: first-year ice, blue: thin ice)

from the three test sites are shown in Figs. 4-6. In general, the classification performance is very good for all three test sites. The classification accuracies of the second step, where the MAP ISODATA classifier was applied to adjust the decision rules, were only slightly improved. The main reason for this is that the decision rules have been selected for the data sets used. If the decision rules are going to be used for data acquired at e.g. slightly different time, it will most likely be necessary to adjust the decision rules by the MAP ISODATA classifier.

\section{CONCLUSIONS}

Based on a comprehensive data analysis of the discrimination potential for the three test sites studied, three different direct hierarchical classification schemes were defined. Different polarimetric parameters were considered for the classification scheme, e.g. backscatter coefficients, correlation coefficients, phase difference, and decomposition parameters, such the entropy, the anisotropy and the alpha angle. The advantage of this approach is clearly that the knowledge available of the polarimetric parameters can be used directly in the classification scheme.

The decision rules showed that the most important parameters are the backscatter coefficients at different polarisations. The polarimetric phase improved the classification performance for thin ice types, only. The classification results showed very good performance of the direct hierarchical classifier with overall classification accuracies from $84 \%$ to $95 \%$. The MAP ISODATA classifier only improved the classification accuracies slightly. For the Baltic Sea and the Beaufort Sea, where both C- and L-band data were available, the L-band gave slightly better results.

\section{REFERENCES}

[1] Rignot, E., and M. R. Drinkwater, "Winter sea ice mapping from multiparameter synthetic aperture radar data”, J. Glaciology, vol. 40, no. 134, pp. 31-45, 1994.

[2] Winebrenner, D. P., L. D. Farmer, and I. R. Joughin, "On the response of polarimetric synthetic aperture radar signatures at $24-\mathrm{cm}$ wavelength to sea ice thickness in Arctic leads", Radio Science, vol. 30, pp.373-402, 1995.

[3] Thomsen, B. B., S. V. Nghiem, and R. Kwok, "Polarimetric C-Band SAR observations of sea ice in the Greenland Sea", IGARSS'98, pp. 2502-2504, 1998.

[4] Thomsen, B. B., L. T. Pedersen, H. Skriver, and W. Dierking, "Polarimetric EMISAR observations of sea ice in the Greenland Sea", in: P. Gudmandsen (ed.), Future Trends in Remote Sensing, pp. 345351, Balkema, Rotterdam, 1998.

[5] Kwok, R., S.V. Nghiem, S.H. Yueh, and D.D. Huynh, "Retrieval of thin ice thickness from multi-frequency polarimetric SAR data", Rem. Sens. Environ., vol. 51, pp. 361-374, 1995.

[6] Thomsen, B. B., "Polarimetric microwave signatures of thin ice", Ph.D. thesis, Report LD 143, Institute of Electromagnetic Systems, Technical University of Denmark, 139 pp., March 2001.

[7] Dierking, W., and J. Askne, "Polarimetric L- and C-band SAR signatures of Baltic sea ice observed during EMAC-95", in: $P$. Gudmandsen (ed.), 'Future Trends in Remote Sensing', pp. 329-336, Balkema, Rotterdam, 1998.

[8] Drinkwater, M. R., R. Kwok, D. P. Winebrenner, and E. Rignot, "Multifrequency polarimetric synthetic aperture radar observations of sea ice”, J. Geophys. Res., Vol. 96(C3), pp. 20679-20298, 1991.

[9] Skriver, H. (ed.), "Application of Synthetic Aperture Radar Polarimetry", Final Report, ESA Contract 15600/01/I-LG, March 2004.

[10] Schou, J., and H. Skriver, "Restoration of Polarimetric SAR Images Using Simulated Annealing”, IEEE Trans. Geosci. Rem. Sens., Vol. 39, pp.2005-2016, 2001. 